\section{RMD Open}

Rheumatic \& Musculoskeletal Diseases

\title{
Bone mineral density in patients with psoriatic arthritis: data from the Nord- Trøndelag Health Study 3
}

Agnete Malm Gulati, ${ }^{1,2}$ Mari Hoff, ${ }^{1,3}$ Øyvind Salvesen, ${ }^{4}$ Alvilde Dhainaut, ${ }^{1,2}$ Anne Grete Semb, ${ }^{5}$ Arthur Kavanaugh, ${ }^{6}$ Glenn Haugeberg ${ }^{2,7}$

To cite: Gulati AM, Hoff M, Salvesen $\emptyset$, et al. Bone mineral density in patients with psoriatic arthritis: data from the Nord-Trøndelag Health Study 3. RMD Open 2017;3:e000413. doi:10.1136/ rmdopen-2016-000413

- Prepublication history for this paper is available online. To view these files please visit the journal online (http://dx.doi. org/10.1136/rmdopen-2016000413).

Received 22 November 2016 Revised 5 February 2017 Accepted 24 February 2017

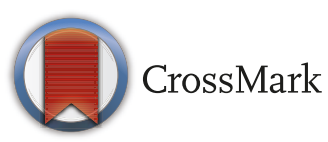

For numbered affiliations see end of article.

Correspondence to Dr Agnete Malm Gulati; agnete. m.gulati@ntnu.no

\section{ABSTRACT}

Background The risk of osteoporosis in patients with psoriatic arthritis (PsA) remains unclear. The aim of this study was to compare bone mineral density (BMD) measured by dual-energy X-ray absorptiometry (DXA) in patients with PsA and controls.

Patients and methods Patients with PsA and controls were recruited from the Nord-Trøndelag Health Study (HUNT) 3.

Results Patients with PsA $(n=69)$ and controls $(n=11703)$ were comparable in terms of age ( 56.8 vs 55.3 years, $p=0.32$ ), gender distribution (females $65.2 \%$ vs $64.3 \%$, $p=0.87)$ and postmenopausal status $(75.6 \%$ vs $62.8 \%$, $\mathrm{p}=0.08$ ). Body mass index (BMI) was higher in patients with PsA compared with controls ( $28.5 \mathrm{vs} 27.2 \mathrm{~kg} / \mathrm{m}^{2}$, $\mathrm{p}=0.01$ ). After adjusting for potential confounding factors (including BMI), BMD was higher in patients with PsA compared with controls at lumbar spine 1-4 (1.213 vs $\left.1.147 \mathrm{~g} / \mathrm{cm}^{2}, \mathrm{p}=0.003\right)$ and femoral neck ( 0.960 vs $0.926 \mathrm{~g} / \mathrm{cm}^{2}, p=0.02$ ), but not at total hip (1.013 vs $\left.0.982 \mathrm{~g} / \mathrm{cm}^{2}, \mathrm{p}=0.11\right)$. Controls had significantly higher odds of having osteopenia or osteoporosis based on measurements of BMD in both the femoral neck $(p=0.001)$, total hip ( $p=0.033)$ and lumbar spine $(p=0.033)$.

Conclusion Our population-based data showed comparable BMD in patients with PsA and controls. This supports that the PsA population is not at increased risk of osteoporosis.

\section{BACKGROUND}

Data on systemic bone loss in patients with psoriatic arthritis (PsA) are conflicting, and population-based data are lacking. ${ }^{1-3}$ It is well documented that patients with rheumatoid arthritis (RA) are at increased risk for osteoporosis, presumably due to factors including systemic and local inflammation, inactivity related to arthritis and treatment with glucocorticoids. ${ }^{45}$ Despite some similar features in clinical presentation and joint damage, substantial differences exist between RA and PsA concerning immunopathogenesis, clinical manifestations and radiographic features. In PsA, activation of both osteoclasts and

\section{Key messages}

What is already known about this subject?

- The risk of osteoporosis in psoriatic arthritis (PSA) remains uncertain.

What does this study add?

- In this population-based study, the bone mineral density (BMD) of 69 patients with PSA, both male and female, was measured with dual-energy $X$-ray absorptiometry and compared with controls without PsA.

- BMD was higher in patients with PsA compared with controls at lumbar spine 1-4 and femoral neck, but not at total hip.

How might this impact on clinical practice?

- This study supports that patients with PsA are not at increased risk of osteoporosis and may follow guidelines for osteoporosis assessment developed for the general population.

osteoblasts can be involved, and as a consequence, patients may show signs of both bone destruction (erosions) and bone formation (periostitis, osteophyte formation).$^{6}$ This in contrast to RA where osteoclast activation is dominating, causing erosions and osteoporosis. $^{7}$

The aim of this study was to compare bone mineral density (BMD) in patients with PsA and controls.

\section{MATERIALS AND METHODS}

Data were retrieved from the Nord-Trøndelag Health Study (HUNT) $3,{ }^{8}$ performed between 2006 and 2008. The study population and validation of diagnoses have been described in detail previously. ${ }^{8}$ The study was approved by the Regional Committee for Medical Research Ethics, South-Eastern Norway (REK number 2010/2661). 


\section{Inclusion of patients and controls}

An experienced rheumatologist reviewed the medical records of persons in HUNT 3 with self-reported PsA, plus self-reported ankylosing spondylitis and psoriasis or self-reported RA and psoriasis to validate PsA. In total, 338 persons in HUNT 3 were found to have PsA according to the Classification of Psoriatic Arthritis criteria. Details on patients with PsA and controls are previously described in details. ${ }^{9}$

An invitation to Dual-energy X-ray absorptiometry (DXA) measurement was sent to 14247 persons in the HUNT 3 population born after 1 January 1921 and living in one of the five largest municipalities in the Nord-Trøndelag county. Eleven thousand seven hundred and seventy-two persons participated $(82.6 \%)$ - 7570 women and 4202 men. Of these, 6887 were invited based on a random sample of the total HUNT cohort, and 4885 were invited based on reporting a wide spectrum of lung symptoms (asthma and chronic obstructive pulmonary disease (COPD)), as the DXA study in HUNT 3 was also initially designed as part of a study on patients with pulmonary disease. This sample included 69 patients with PsA (36 invited by random selection and 33 because of self-reported pulmonary symptoms) with age between 20 to 95 years. Controls were all other participants in the HUNT 3 study.

\section{Measurement of variables}

Information about risk factors and disease was collected by self-administered questionnaires, clinical measurements and blood samples. Data on medication use, clinical and disease spesific charcateristics among the PsA patients were collected from the patient's hospital journals. Measurements of height and weight were performed with lightweight clothing and no shoes. Females were asked about age at cessation of menstrual cycle.

DXA measurements were performed in the lumbar spine (L1-L4) and hip (femoral neck and total hip) using a Lunar/Prodigy (GE Healthcare) DXA machine. Lumbar spine BMD was calculated as the mean of the BMD score in L1-L4. We preferably used measurements from the left hip. Bone density was expressed as $\mathrm{g} /$ $\mathrm{cm}^{2}$ and T-score (SD from the mean of a healthy young female population). The data for T-score estimation were provided by the manufacturer. Regular phantom calibration of the densitometer was performed according to the existing densitometry procedures and quality assessment guidelines at HUNT.

The World Health Organization (WHO) definition was applied for osteoporosis (T-score $\leq-2.5 \mathrm{SD}$ ), osteopenia (T-score between -1.0 and $-2.5 \mathrm{SD}$ ) and normal BMD (T-score $\geq-1.0 \mathrm{SD}$ ) (WHO, 1994). Details on the registration of variables have been published previously. ${ }^{10}$

\section{Statistical analysis}

All statistical analyses were performed using the SPSS V.21. A two-sided statistical significance level was defined as $\mathrm{p}<0.05$. Continuous variables were analysed using an unpaired two-tailed t-test for normally distributed data. The $\chi^{2}$ test, or Fisher exact test when small numbers, was used to examine the associations between categorical variables. A multivariable linear regression model was used to assess the relationship between PsA and BMD, controlling for potential confounders (age, sex, BMI, smoking status, physical activity, asthma/ COPD and reason for invitation to DXA measurement). Ordinal logistic regression was used to compare the frequency of osteoporosis in patients with PsA and controls, after assessment of parallel lines.

\section{RESULTS}

As shown in table 1 , there were no differences between patients with PsA and control subjects concerning age, sex, postmenopausal status, height, smoking, ever use of asthma or COPD medication and C-reactive protein (CRP).

A statistically significant difference between patients with PsA and controls was seen for weight $(83.8 \mathrm{~kg}$ vs $77.9 \mathrm{~kg}$, $\mathrm{p}<0.01)$, BMI $\left(28.5 \mathrm{~kg} / \mathrm{m}^{2}\right.$ vs $\left.27.2 \mathrm{~kg} / \mathrm{m}^{2}, \mathrm{p}=0.01\right)$ and self-reported asthma (37.7\% vs $26.8 \%, \mathrm{p}=0.04)$ and COPD $(14.5 \%$ vs $7.1 \%, \mathrm{p}=0.02)$. Mean disease duration for patients with PsA was $8.3 \pm 6.8$ years. Among patients with PsA, 14 (20.3\%) had axial involvement in addition to peripheral joint disease. We excluded 60 persons in the control group with bilateral hip prostheses or invalid measurements from further analyses of BMD of the hip. BMD values and T-scores for patients with PsA and controls are presented in table 2.

When adjusting for potential confounding factors listed in table 2, BMD was significantly higher in patients with PsA compared with controls in spine L1-L4 (1.213 vs $1.147 \mathrm{~g}$ / $\left.\mathrm{cm}^{2}, \mathrm{p}=0.003\right)$ and femoral neck $\left(0.960\right.$ vs $0.926 \mathrm{~g} / \mathrm{cm}^{2}$, $\mathrm{p}=0.02$ ) but not in total hip (1.013 vs $0.982 \mathrm{~g} / \mathrm{cm}^{2}, \mathrm{p}=0.11$ ). In females, the PsA group had significantly higher BMD in the lumbar spine (mean difference $0.056,95 \%$ CI 0.003 to $1.109, \mathrm{p}=0.04$ ) but not in the hip. Postmenopausal patients with PsA ( $\mathrm{n}=34)$ had significantly higher BMD than controls at femoral neck (mean difference $0.071,95 \%$ CI 0.025 to $0.117, \mathrm{p}=0.043$ ) and spine (mean difference $0.106,95 \% \mathrm{CI}$ 0.045 to $0.166, \mathrm{p}=0.009$ ) when controlling for potential confounding factors (data not shown).

Neither univariable nor multivariable linear regression models (controlling for age, sex, BMI, smoke and asthma diagnosis) showed an association between disease duration and BMD (adjusted $\mathrm{p}$ values for femoral neck BMD 0.93, total hip BMD 0.98, spine L1-L4 0.09).

As shown in table 3, the odds of being classified as having osteopenia or osteoporosis was greater for the control subjects than the patients with PsA (ordinal logistic regression).

\section{DISCUSSION}

This population-based cohort study found a higher BMD in the lumbar spine and femoral neck in individuals with PsA compared with individuals without PsA. Our findings are in line with other publications that report comparable BMD in 
Table 1 Demographic and clinical characteristics in patients with psoriatic arthritis and controls with bone density measurement in the HUNT 3 study. Results are mean $( \pm S D)$ for continuous variables or absolute values (percentages) for categorical variables

\begin{tabular}{lllc}
\hline $\begin{array}{l}\text { Demographic } \\
\text { variables }\end{array}$ & $\begin{array}{l}\text { Psoriatic } \\
\text { arthritis } \\
\mathbf{n}=69\end{array}$ & $\begin{array}{l}\text { Controls } \\
\mathbf{n}=11703\end{array}$ & $\mathbf{p ~ V a l u e}^{*}$ \\
\hline Female & $45(65.2)$ & $7525(64.3)$ & 0.87 \\
$\begin{array}{l}\text { Postmenopausal } \\
\text { females }\end{array}$ & $34(75.6)$ & $4722(62.8)$ & 0.08 \\
\hline Age, years & $56.8(12.5)$ & $55.3(16.5)$ & 0.32 \\
\hline Weight, kg & $83.8(16.3)$ & $77.9(15.4)$ & $<0.01$ \\
\hline Height, m & $1.70(0.09)$ & $1.69(0.09)$ & 0.09 \\
\hline BMI, kg/m ${ }^{2}$ & $28.5(4.3)$ & $27.2(4.5)$ & 0.01 \\
\hline Daily smoking & $18(26.1)$ & $2814(24.0)$ & 0.69 \\
\hline Physical & $40(58)$ & $6848(58.5)$ & 0.93 \\
\hline activity $\geq 2$ times per & & &
\end{tabular}

activity $\geq 2$ times per

week

\begin{tabular}{|c|c|c|c|}
\hline Asthma ever & $26(37.7)$ & $3138(26.8)$ & 0.04 \\
\hline $\begin{array}{l}\text { COPD/emphysema } \\
\text { ever }\end{array}$ & $10(14.5)$ & $830(7.1)$ & 0.02 \\
\hline $\begin{array}{l}\text { Ever use of asthma/ } \\
\text { COPD medication last } \\
5 \text { years }\end{array}$ & 23 (33.3) & 2800 (23.9) & 0.07 \\
\hline $\begin{array}{l}\text { C-reactive protein, } \\
\mathrm{mg} / \mathrm{L}\end{array}$ & $3.9(4.9)$ & $2.9(5.8)$ & 0.17 \\
\hline \multicolumn{4}{|l|}{ Self-reported fractures } \\
\hline Forearm (PsA n=65) & $11(16.9)$ & 1938 (17.3) & 0.93 \\
\hline Hip (PsA n=65) & $1(1.5)$ & $187(1.7)$ & $1.00 \dagger$ \\
\hline Spine (PsA n=63) & $3(4.8)$ & $649(6.0)$ & $1.00 \dagger$ \\
\hline $\begin{array}{l}\text { Self-reported } \\
\text { osteoporosis (PsA } \\
n=64)\end{array}$ & $6(9.4)$ & $538(4.8)$ & 0.08 \\
\hline $\begin{array}{l}\text { Ever use of hormone } \\
\text { replacement therapy } \\
\text { among females }\end{array}$ & $\begin{array}{c}16 / 30 \\
(53.3 \%)\end{array}$ & $\begin{array}{l}1541 / 3766 \\
(40.9)\end{array}$ & 0.17 \\
\hline Disease duration, years & $8.3(6.8)$ & NA & \\
\hline $\begin{array}{l}\text { Peripheral joint } \\
\text { involvement }\end{array}$ & $69(100)$ & NA & \\
\hline
\end{tabular}

\begin{tabular}{|lll}
\hline Joint involvement & & \\
\hline Isolated DIP joint & $1(1.4)$ & NA \\
\hline Monoarthritis & $1(1.4)$ & \\
\hline Oligoarthritis & $44(63.8)$ & \\
Polyarthritis & $23(33.3)$ & \\
Axial involvement & $14(20.3)$ & NA \\
Entesitis & $43(62.3)$ & NA \\
Ever use of peroral & & \\
steroids & & \\
$\quad$ Previous & $25(36.2)$ & NA \\
$\quad$ Current & $4(5.8)$ & \\
\hline
\end{tabular}

Ever users of anti-TNF therapy

Continued
Table 1 Continued

\begin{tabular}{clll}
\hline $\begin{array}{l}\text { Demographic } \\
\text { variables }\end{array}$ & $\begin{array}{l}\text { Psoriatic } \\
\text { arthritis } \\
\mathbf{n}=69\end{array}$ & $\begin{array}{l}\text { Controls } \\
\mathbf{n}=11703\end{array}$ & p Value $^{*}$ \\
\hline Previous & $2(2.9)$ & NA & \\
Current & $5(7.2)$ & &
\end{tabular}

Ever use of

methotrexate

\begin{tabular}{|c|c|c|}
\hline Previous & $11(15.9)$ & NA \\
\hline Current & $18(26.1)$ & \\
\hline \multicolumn{3}{|c|}{$\begin{array}{l}\text { Ever use of synthetic } \\
\text { DMARDS other than } \\
\text { methotrexate }\end{array}$} \\
\hline Leflunomide & 15 (21.7) & NA \\
\hline Salazopyrin & 7 (10.1) & \\
\hline \multicolumn{3}{|c|}{ Ever use of NSAIDs } \\
\hline previous & 14 (20.3) & NA \\
\hline current & $44(63.8)$ & \\
\hline
\end{tabular}

${ }^{*} \chi^{2}$ test for counts and independent samples t-test for continuous variables,

†Fisher's exact test due to small numbers.

Anti-TNF therapy, antitumour necrosis factor therapy; BMI, body mass index; COPD, chronic obstructive pulmonary disease; DIP, distal interphalangeal; DMARD, disease modifying antirheumatic drug; DXA, dual-energy X-ray absorptiometry; HUNT, Nord-Trøndelag Health Study; NSAIDs, non-steroidal anti-inflammatory drugs; NA, not applicable.

patients with PsA and the general population. ${ }^{311-14}$ However, comparing results across studies is difficult, as outcomes and comparison groups differ. ${ }^{2} \mathrm{~A}$ rather low proportion of patients with PsA in this study were currently using tumour necrosis factor (TNF)-inhibitors. This may be explained by the inclusion being performed between 2006 and 2008 when use of TNF-inhibitors was still low in PsA patients in Norway. As the patients with PsA in our study were identified from a population survey and had similar CRP as the control group, we also suspect a relatively low disease activity. The patients with PsA had higher BMI, which is associated with greater BMD in the general population. ${ }^{15}$ However, controlling for BMI in a multivariable linear regression model did not influence the results on BMD in our study. Further, the spine may be affected by new bone formation in PsA, which should be taken into account when evaluating BMD data from the lumbar spine. ${ }^{2}$

Higher BMD in PsA compared with RA has been reported. ${ }^{16}{ }^{17}$ Further, it is well documented that patients with RA are at increased risk for osteoporosis and fracture. ${ }^{518}$ The pathophysiological mechanisms that affect bone appear to be different in PsA and RA. In RA, the inflammatory process causes an increased stimulation of the osteoclasts, together with a downregulation of the osteoblasts, whereas in PsA both osteoclasts and osteoblasts are stimulated. ${ }^{19}$ Autoantibodies such as anticyclic citrullinated peptide antibodies are known to represent a higher risk of developing bone erosions by directly stimulating the differentiation of 
Table 2 Bone mineral density in patients with psoriatic arthritis and controls in the HUNT 3 study

\begin{tabular}{|c|c|c|c|c|c|}
\hline $\begin{array}{l}\text { DXA } \\
\text { Females and males }\end{array}$ & $\begin{array}{l}\text { PsA } \\
\mathrm{n}=69\end{array}$ & $\begin{array}{l}\text { Controls } \\
n=11703\end{array}$ & $\begin{array}{l}\text { Mean difference }(95 \% \mathrm{Cl}) \\
\text { (PsA vs controls) }\end{array}$ & p Value* & p Valuet \\
\hline \multicolumn{6}{|l|}{ Left femoral neck } \\
\hline BMD & $0.960(0.134)$ & $0.926(0.157)$ & $0.034(-0.003$ to 0.071$)$ & 0.07 & 0.02 \\
\hline T-score & $-0.42(0.99)$ & $-0.70(1.24)$ & 0.30 (0.04 to 0.52$)$ & 0.02 & 0.02 \\
\hline \multicolumn{6}{|l|}{ Left total hip } \\
\hline BMD & $1.013(0.141)$ & $0.982(0.158)$ & $0.030(-0.007$ to 0.067$)$ & 0.11 & 0.11 \\
\hline T-score & $-0.15(1.04)$ & $-0.41(1.22)$ & $0.26(-0.03$ to 0.54$)$ & 0.09 & 0.11 \\
\hline \multicolumn{6}{|l|}{ Spine L1-L4 } \\
\hline BMD & $1.213(0.177)$ & $1.147(0.183)$ & 0.065 (0.021 to 0.108$)$ & 0.003 & 0.003 \\
\hline T-score & $0.15(1.43)$ & $-0.39(1.50)$ & 0.55 (0.19 to 0.91$)$ & 0.003 & 0.003 \\
\hline Females & $\begin{array}{l}\text { PsA } \\
n=45\end{array}$ & $\begin{array}{l}\text { Controls } \\
n=7525\end{array}$ & $\begin{array}{l}\text { Mean difference }(95 \% \mathrm{Cl}) \\
\text { (PsA vs controls) }\end{array}$ & p Value* & p Value \\
\hline \multicolumn{6}{|l|}{ Left femoral neck } \\
\hline BMD & $0.921(0.106)$ & $0.897(0.155)$ & $0.024(-0.008$ to 0.056$)$ & 0.14 & 0.19 \\
\hline T-score & $-0.487(0.88)$ & $-0.69(1.29)$ & $0.20(-0.06$ to 0.47$)$ & 0.14 & 0.19 \\
\hline \multicolumn{6}{|l|}{ Left total hip } \\
\hline BMD & $0.973(0.115)$ & $0.946(0.153)$ & $0.026(-0.007$ to 0.061$)$ & 0.13 & 0.30 \\
\hline T-score & $-0.22(0.96)$ & $-0.45(1.28)$ & $0.22(-0.065$ to 0.51$)$ & 0.13 & 0.30 \\
\hline \multicolumn{6}{|l|}{ Spine L1-L4 } \\
\hline BMD & $1.174(0.148)$ & $1.118(0.181)$ & 0.056 (0.003 to 0.109$)$ & 0.04 & 0.04 \\
\hline T-score & $-0.05(1.23)$ & $-0.52(1.51)$ & $0.46(0.02$ to 0.91$)$ & 0.04 & 0.04 \\
\hline
\end{tabular}

Mean $( \pm \mathrm{SD})$.

*Independent samples t-test,

†Linear regression analysis with adjustments made for age, sex, BMI, physical activity, smoking, asthma/COPD and reason for invitation to DXA fLinear regression analysis with adjustments made for age, BMI, physical activity, smoking, asthma/COPD and reason for invitation to DXA.

BMD, bone mineral density; BMI, body mass index; DXA, dual-energy X-ray absorptiometry; COPD, chronic obstructive pulmonary disease; HUNT,

Nord-Trøndelag Health Study; PsA, psoriatic arthritis.

osteoclasts and promoting bone resorption..$^{20}$ In PsA, there is an absence of recognised autoantibodies. The clinical implications of these pathophysiological differences are that osteoporosis and joint erosions are more prominent in RA, whereas PsA is also characterised by new bone formation. ${ }^{19}$
This may explain the higher BMD seen in patients with PsA compared with patients without PsA in our population cohort, particularly in the spine where syndesmophytes are common in PsA. In our PsA cohort, 14 patients (20.3\%) had axial involvement based on clinical and radiological

Table 3 Osteoporosis, osteopenia and normal bone mineral density (BMD) among patients with psoriatic arthritis and controls in the HUNT 3 study: Ordinal regression shows higher odds of being classified as having osteopenia or osteoporosis for the control group

\begin{tabular}{|c|c|c|c|c|}
\hline Based on T-score femoral neck & PsAoriatic Arthritis & Controls & Overall p- vValue* & Overall $p$-vValue ${ }^{* *} \dagger$ \\
\hline Osteoporosis & $1(1.4)$ & $739(6.4)$ & 0.002 & 0.001 \\
\hline Osteopenia & $15(21.7)$ & 4065 (35.4) & & \\
\hline \multicolumn{5}{|l|}{ Based on T-score total hip } \\
\hline Osteoporosis & $1(1.4)$ & $474(4.1)$ & 0.024 & 0.033 \\
\hline Osteopenia & $12(17.4)$ & $3143(27.5)$ & & \\
\hline \multicolumn{5}{|l|}{ Based on T-score spine L1-L4 } \\
\hline Osteoporosis & $3(4.4)$ & $903(7.8)$ & 0.021 & 0.033 \\
\hline Osteopenia & $11(16.2)$ & $3065(26.4)$ & & \\
\hline Normal BMD & $54(79.4)$ & $7629(65.8)$ & & \\
\hline
\end{tabular}

Frequency (percentage).

*Ordinal regression with no adjustments made,

tOrdinal regression with adjustments made for age (continuous), BMI, physical activity, smoking, asthma/COPD and reason for invitation to DXA (randomly or based on self-reported pulmonary symptoms).

BMD, bone mineral density; BMI, body mass index; COPD, chronic obstructive pulmonary disease; DXA, dual-energyX-ray absorptiometry; HUNT,

Nord-Trøndelag Health Study; PsA, psoriatic arthritis. 
findings, but we were unable to obtain X-ray of the spine for all patients with PsA to control for syndesmophytes or degeneration of the spine. New bone formation may also form at the hip, and may therefore in theory also affect the BMD value of both femoral neck and total hip. ${ }^{21}$

High correlation between BMD measurements and bone strength in hip and spine has been demonstrated in in vitro studies, and a strong association between BMD and risk of fracture exists. ${ }^{22}$ However, besides $\mathrm{BMD}$, there are several other risk factors for fracture. One study found higher cortical porosity and lower cortical bone density of the distal radius on high-resolution CT in patients with PsA despite a normal BMD. ${ }^{23}$ This may affect the cortical bone quality and predispose the bone to fractures. Other studies have reported higher frequency of fractures in PsA despite comparable BMD. ${ }^{13} 14$

The strengths of this study include the population-based study design and the use of objective criteria for the PsA diagnoses. A limitation is the relatively small number of PsA cases. We did not have access to clinical data on disease activity of the patients with PsA, but CRP was similar in the two groups. Unfortunately, we had limited information about steroid use in the control group and could therefore not include this variable in our regression models. In addition, we did not examine radiological images of the patients with PsA to control for syndesmophytes in the spine or new bone formation of the hip area, or calcifications of the aorta, which may influence the BMD values at these sites.

\section{CONCLUSION}

Our population-based data showed similar BMD in patients with PsA and controls. Slightly higher BMD values at femoral neck and lumbar spine were observed in patients with PsA. A higher proportion of the PsA population had a normal BMD. Thus our findings support that patients with PsA do not seem to have a significantly increased risk of osteoporosis compared with the background population.

\begin{abstract}
Author affiliations
'Department of Rheumatology, St Olavs Hospital, Trondheim, Norway

${ }^{2}$ Department of Neuroscience, Norwegian University of Science and Technology, Trondheim, Norway

${ }^{3}$ Department of Public Health and General Practice, Norwegian University of Science and Technology, Trondheim, Norway

${ }^{4}$ Unit for Applied Clinical Research, Norwegian University of Science and Technology, Trondheim, Norway

${ }^{5}$ Department of Rheumatology, Diakonhjemmet Hospital, Oslo, Norway

${ }^{6}$ Department of Rheumatology, Allergy and Immunology, University of California, San Diego, California, USA

${ }^{7}$ Department of Rheumatology, Martina Hansens Hospital, Brum, Norway

Acknowledgements The Nord-Trøndelag Health Study (The HUNT Study) is a collaboration between HUNT Research Centre (Faculty of Medicine, Norwegian University of Science and Technology NTNU), Nord-Trøndelag County Council, Central Norway Health Authority and the Norwegian Institute of Public Health. We thank clinicians and other employees at Nord-Trøndelag Hospital Trust for contributing to data collection in this research project. We also thank Sasha Gulati for assistance with writing of the manuscript.
\end{abstract}

Contributors AMG: study design, statistical analyses, interpretation of the data and writing. MH: study design, collection of data, statistical analyses, interpretation of the data and writing. $\emptyset \mathrm{S}$ : statistical analyses and interpretation of the data. AD: study design, interpretation of the data and writing. AGS: interpretation of the data and writing. AK: interpretation of the data and writing. GH: study design, interpretation of the data and writing. All authors contributed with critical review of the paper, read and approved the final manuscript.

Funding The Liaison Committee between the Central Norway Regional Health Authority (RHA) and the Norwegian University of Science and Technology (NTNU). The funder had no involvement in study design, data collection, data analysis, manuscript preparation and/or publication decisions.

Competing interests None declared.

Ethics approval Regional Committee for Medical Research Ethics, South-Eastern Norway (REK number 2010/2661.

Provenance and peer review Not commissioned; externally peer reviewed.

Open Access This is an Open Access article distributed in accordance with the Creative Commons Attribution Non Commercial (CC BY-NC 4.0) license, which permits others to distribute, remix, adapt, build upon this work non-commercially, and license their derivative works on different terms, provided the original work is properly cited and the use is non-commercial. See: http://creativecommons.org/ licenses/by-nc/4.0/

(C) Article author(s) (or their employer(s) unless otherwise stated in the text of the article) 2017. All rights reserved. No commercial use is permitted unless otherwise expressly granted.

\section{REFERENCES}

1. Frediani $B$, Allegri A, Falsetti $P$, et al. Bone mineral density in patients with psoriatic arthritis. J Rheumatol 2001;28:138-43.

2. Chandran S, Aldei A, Johnson SR, et al. Prevalence and risk factors of low bone mineral density in psoriatic arthritis: a systematic review. Semin Arthritis Rheum 2016;46:174-82.

3. Nolla JM, Fiter J, Rozadilla A, et al. Bone mineral density in patients with peripheral psoriatic arthritis. Rev Rhum Engl Ed 1999;66:457-61.

4. Gough AK, Lilley J, Eyre S, et al. Generalised bone loss in patients with early rheumatoid arthritis. Lancet 1994;344:23-7.

5. Haugeberg G, Ørstavik RE, Uhlig T, et al. Bone loss in patients with rheumatoid arthritis: results from a population-based cohort of 366 patients followed up for two years. Arthritis Rheum 2002;46:1720-8.

6. Kruithof E, Baeten D, De Rycke L, et al. Synovial histopathology of psoriatic arthritis, both oligo- and polyarticular, resembles spondyloarthropathy more than it does rheumatoid arthritis. Arthritis Res Ther 2005; 7:R569-80.

7. Roux C. Osteoporosis in inflammatory joint diseases. Osteoporos Int 2011;22:421-33.

8. Krokstad S, Langhammer A, Hveem K, et al. Cohort Profile: the HUNT Study, Norway. Int J Epidemio/ 2013;42:968-77.

9. Hoff M, Gulati AM, Romundstad PR, et al. Prevalence and incidence rates of psoriatic arthritis in central Norway: data from the NordTrøndelag health study (HUNT). Ann Rheum Dis 2015;74:60-4.

10. Gulati AM, Semb AG, Rollefstad S, et al. On the HUNT for cardiovascular risk factors and disease in patients with psoriatic arthritis: population-based data from the Nord-Trøndelag Health Study. Ann Rheum Dis 2016;75:819-24.

11. Del Puente A, Esposito A, Costa L, et al. Fragility fractures in patients with Psoriatic Arthritis. J Rheumatol Supp/ 2015;93:36-9.

12 Grazio S, Cvijetić S, Vlak T, et al. Osteoporosis in psoriatic arthritis: is there any? Wien Klin Wochenschr 2011;123:743-50.

13. Pedreira PG, Pinheiro MM, Szejnfeld VL. Bone mineral density and body composition in postmenopausal women with psoriasis and psoriatic arthritis. Arthritis Res Ther 2011;13:R16.

14. Riesco M, Manzano F, Font P, et al. Osteoporosis in psoriatic arthritis: an assessment of densitometry and fragility fractures. Clin Rheumatol 2013:32:1799-804.

15. Felson DT, Zhang Y, Hannan MT, et al. Effects of weight and body mass index on bone mineral density in men and women: the Framingham study. J Bone Miner Res 1993;8:567-73.

16. Kocijan R, Finzel S, Englbrecht M, et al. Differences in bone structure between rheumatoid arthritis and psoriatic arthritis patients relative to autoantibody positivity. Ann Rheum Dis 2014;73:2022-8.

17. Harrison BJ, Hutchinson CE, Adams J, et al. Assessing periarticular bone mineral density in patients with early psoriatic arthritis or rheumatoid arthritis. Ann Rheum Dis 2002;61:1007-11. 
18. Haugeberg G, Ørstavik RE, Kvien TK. Effects of rheumatoid arthritis on bone. Curr Opin Rheumatol 2003;15:469-75.

19. Finzel S, Kraus S, Schmidt S, et al. Bone anabolic changes progress in psoriatic arthritis patients despite treatment with methotrexate or tumour necrosis factor inhibitors. Ann Rheum Dis 2013;72:1176-81.

20. Sokolove J, Pisetsky D, Bone loss pain. Bone loss, pain and inflammation: three faces of ACPA in RA pathogenesis. Ann Rheum Dis 2016;75:637-9.
21. Lories RJ, Haroon N. Bone formation in axial spondyloarthritis. Best Pract Res Clin Rheumatol 2014;28:765-77.

22. Marshall $D$, Johnell $O$, Wedel $H$. Meta-analysis of how well measures of bone mineral density predict occurrence of osteoporotic fractures. BMJ 1996:312:1254-9.

23. Zhu TY, Griffith JF, Qin L, et al. Density, structure, and strength of the distal radius in patients with psoriatic arthritis: the role of inflammation and cardiovascular risk factors. Osteoporos Int 2015;26:261-72. 